\title{
Hekimlerin Sağlık Bilgisi Arayan Hastaya Uyguladıkları İletişim Stratejileri
}

\section{Communication Strategies Applied by Physicians to the Health Information Seeking Patients}

\author{
Kadriye AVCI (ORCID ID: https://orcid.org/0000-0001-8894-4142) \\ Mehmet MERGEN² (ORCID ID: https://orcid.org/0000-0002-2043-5680) \\ Gizem ÇAL (ORCID ID: https://orcid.org/0000-0002-6811-822X) \\ Müberra TORUN² (ORCID ID: https://orcid.org/0000-0001-9428-1306) \\ Seyit Ahmet KORUR² (ORCID ID: https://orcid.org/0000-0003-4854-4544) \\ Osman Metehan KARCI (ORCID ID: https://orcid.org/0000-0002-0870-9159) \\ ${ }^{1}$ Afyonkarahisar Sağlık Bilimleri Üniversitesi Tıp Fakültesi, Halk Sağlığı Anabilim Dalı, Afyonkarahisar \\ ${ }^{2}$ Afyonkarahisar Sağlık Bilimleri Üniversitesi Tıp Fakültesi Öğrencisi, Afyonkarahisar \\ Sorumlu Yazar: Doç Dr Kadriye Avc1 \\ Afyonkarahisar Sağlık Bilimleri Üniversitesi Tıp Fakültesi Halk Sağlığı Anabilim Dalı Afyonkarahisar \\ e-mail:drkavci@yahoo.com
}

Anahtar Sözcükler:

Sağlık iletişimi, Bilgi arayan davranış, İletişim yöntemleri

Keywords:

Health communication,

Information seeking

behavior, Communication methods

Gönderilme Tarihi

Submitted:08.03.2019

Kabul Tarihi

Accepted: 21.10.2019

\section{ÖZET:}

Amaç: Günümüzde sağlık bilgisi araştırma davranışı hastalar arasında çok yaygındır. Hastaların bu davranışını inceleyen pek çok çalışma vardır, ancak bilgi arayıp gelen hastaya hekimin tutumuna yönelik çok sınırlı çalışma vardır. Bu çalışmanın amacı, internetten bilgi edinen hastalarda, hekimlerin kullandığı iletişim stratejilerini tanımlamaktır.

Gereç ve Yöntem: Bu araştırma, Ocak-Şubat 2018'de yapılan nitel bir çalışmadır. Çalışmamızda Afyonkarahisar Sağlık Bilimleri Üniversitesi Tıp Fakültesi'nden 30 öğretim üyesi ile görüşülmüştür. Görüşmelerde öncelikle öğretim üyeleri çalışma hakkında bilgilendirildi ve rızaları dahilinde ses kaydı alınmıştır. Bu görüşmelerde yarı yapılandırılmış görüşme tekniği kullanılmıştır. Açık uçlu sorularla derinlemesine görüşme metodu kullanılmıştır. Görüşmelerde iki ana soru sorulmuştur: 1) Sağlık bilgisi arayıp gelen hastaya nasıl yaklaşırsınız? ve 2) Bu konuda başınızdan geçen bir örnek olay var mıdır? İçerik analizinden sonra hekimlerin bu tür hastalara karş1 tutumlarına göre gruplandırılmış ve alıntılar yapıllmıştır.

Künye: Avcı K, Mergen M, Çal G, Torun M, Korur S, Karcı O. Hekimlerin Sağlık Bilgisi Arayan Hastaya Uyguladıkları İletişim Stratejileri. Tıp Eğitimi Dünyası. 2020;19(57):139-146 
Bulgular: $\mathrm{Bu}$ çalışmada hekimler, bilgi isteyen hastalara karşı geliştirdikleri iletişim stratejilerine göre beş grupta toplanmıştır: Doğru bilgileri destekleyen $(\% 43,3)$, reddedici $(\% 26,7)$, tanıdan sonra destekleyen (\% 13,3), destekleyen $(\% \quad 10,0)$ ve tepkisiz grup (\% 6,7). Doğru bilgiyi destekleyenler, sadece hekimin onayladığı kaynaklardan elde edilen sağlik bilgisini kabul eden gruptur. Reddedici gurup, sağlık bilgisi arayan hastanın, bilginin kaynağ1 ve doğruluğuna bakmaksızın, direkt aradığı bilgiyi reddetmektedir. Üçüncü grup tanı konduktan sonraki süreçte bilgi aramayı desteklemektedir. Destekleyici grup, sağlık bilgisi arama davranışını direkt destekleyen gruptur. Son grup ise hastanın bilgi arayışına karşı tepkisizdir.

Sonuç: $\mathrm{Bu}$ çalışmada, hekimlerin çoğunun sağlık bilgisi arayışı davranışına destekleyici bir tutumu olduğu görülmüştür. İnternetten bilgi edinen hastaların ihtiyaçlarını karşılamak için hekim-hasta ilişkisi modelinin nasıl geliştirilmesi gerektiği konusunda daha fazla araştırmaya ihtiyaç vardır.

\section{ABSTRACT:}

Objective: Today, health-seeking behavior is very common among patients. There are many studies examining this behavior of patients, but there are very limited studies on the attitudes of the physician to the patient who sought information. The aim of this study was to describe the communication strategies used by physicians for Internet-informed patients.

Materials and Methods: This research is a qualitative study conducted in JanuaryFebruary 2018. In our study, 30 faculty members from Afyonkarahisar Health Sciences University, Faculty of Medicine have been interviewed. The participants were informed about the study and the interviews were voice- recorded with their consent. Semi-structured interview technique was used in these interviews. The in-depth interview method was used with open-ended questions. Two main questions were asked during the interviews: 1) How would you approach the patient who sought health information? and 2) Is there a case in hand? After content analysis, physicians were grouped according to their attitudes towards Internetinformed patients and quotations were made.

Results: In this study, physicians were gathered in five groups according to the communication strategies they developed against the patient seeking information: Supporting the correct information (43.3\%), refused (26.7\%), supporting after diagnosis (13.3\%), supporting (10.0\%) and unresponsive group (6.7\%). The supporters of the right information are those who accept only the health information obtained from the sources approved by the physician. The rejecting group rejects the information directly sought by the patient seeking health information, regardless of the source and accuracy of the information. The third group supports the search for information in the process after diagnosis. The supporting group is the group that directly supports health information-seeking behavior. The last group is unresponsive to the patient's search for information.

Conclusion: In this study, it was observed that most of the physicians had a supportive attitude towards health information seeking behavior of patients. Further research is needed on how a physician-patient relationship model should be developed in order to meet the needs of patients who Internet-informed patients.

\section{GİRIŞ}

İnsanlar, bilgi tüketici özellikleri ile karakterizedir. Bilgiyi aktif olarak araştırır, toplar, tüketir ve gerektiğinde paylaşır 
(1). Günümüzde, bilginin elde edilmesi ve erişiminin artımıyla birlikte, kişilerin kendi sağlıklarını yönetmeye ve hastalıklardan korunmaya odaklanması, sağlık alanında da bilgi araştırılmasını ilgi çekici hale getirmiştir (2). Sağlık bilgisi arama davranışı (SBAD: Health information Seeking Behaviour), sağlıkla ilgili belli bir olay karşısında, endişe veya ihtiyaçtan kaynaklanan, aktif olarak spesifik bilgi toplama süreci olarak tanımlanabilir $(3,4)$. Günümüzde hasta ile hekim ortak karar aldığ 1 , modern hasta-hekim iletişimine doğru bir eğilim vardır. $\mathrm{Bu}$ iletişim şekli çerçevesinde, hastanın aktif katılımının sağlanması ve bilinçli olması çok önemlidir (3). SBAD'da bilinçli olmak hastanın tercihidir, pasif olarak bilgiye maruziyet yoktur, kişi gerekli bilgiyi bir amaç için ve aktif olarak arar.

Hasta, hekime başvurmadan önce ya da hekimden hastalığını öğrendikten sonra arama davranışını gerçekleştirir. Elde edilen sağlık bilgisinin içeriği ve kalitesi, hastanın tıbbi bilgiyi kullanma ve kendileriyle ilişkilendirme becerisine göre, bu davranış olumlu ya da olumsuz sonuçlanabilir (5).

Doğru sağlık bilgisi kişilere destek verici bilgi sağlar, kişilerin sağlık durumlarıyla ilgili şüphelerinin azalmasını ve daha kolay başa çıkmalarını sağlar $(6,7)$. Bilgi arayan hastaya, hastalığıyla ilgili yetki ve sorumluluk sağlar, utandırıcı sorularına cevap bulmaya çalışır ve hekime düşen bilgi verme yükünü azaltabilir. Buna ek olarak internet, kendilerini benzer sağlık durumlarında bulan, hastalara sağlık güçlüğü çeken bireyler için güçlü, yüksek erişilebilir bir destek tabanı oluşturan geniş bir hasta topluluğu sağlar. Ayrıca, artan hasta bilgisinin hekim hatalarını azaltmaya yardımcı olması mümkündür (8). Bilgi edinen hastalar sağlık hizmetleri kaynaklarını daha doğru kullanabilir ve kendilerine önerilen tedavi planlarına uyma olasılıkları daha yüksektir. Bilgi sayesinde hastaların öz-farkındalığı gelişerek hastalıkları üzerindeki kontrolü artabilir. Bilgi edinmiş hastaya klinik karar verme aşamasında daha az vakit harcanmaktadır. Özellikle hekime ziyaret sonrası bilgi edinen hasta, kendini daha rahat hissedebilir ve tedavisinden daha fazla tatmin olabilir (9). Bunun yanında doğru olmayan ya da yanlış yorumlanan sağlık bilgisi ise sağlık davranışlarını ve sağlık sonuçlarını tehlikeye atabilir ya da klinik müdahaleler için uygun olmayan talepler ile sonuçlanabilir $(6,7)$. Son zamanlarda hastalar hekime gelmeden önce daha fazla bilgiye erişebilmektedir. Karmaşık bilgiler edinmiş meraklı hastalara da hekimin sınırlı vakti vardır (10). Hastaların gereksiz sorular1, gereksiz test ve tedavi isteklerinden kaynaklanan zaman ve para kaybına yol açmaktadır (8). Aslında bu konudaki temel sorun internetteki bilgilerin kalitesi ve doğruluğudur. İnternetteki sağlık bilgisi yanıltıcı veya yanlış yorumlanabilir ve bu da uygun olmayan isteklere yol açabilir. Yanlış bilgilendirme gereksiz anksiyete, morbidite ve hatta mortaliteye neden olabilir (9).

Sağlık bilgisi arama davranışı, hasta-hekim ilişkisini de etkilemekte ve bazı konularda hekimi endişelendirmektedir; çünkü hastanın bilgi kaynağı yanlış olabilir, yanlış anlayabilir ya da öğrendiği bilgi yanlış olabilir. Hastanın kafasında birçok soru oluşabilir ve bu da hem görüşmenin uzamasına hem de hastada gereksiz anksiyeteye sebep olabilir. Ayrıca hastanın hekime duyduğu güven etkilenebilir ve olumsuz bir durumda hasta ve hekim arasında tartışmalar nedeniyle, hasta memnuniyetsizliği ile sonuçlanabilir. $\mathrm{Bu}$ nedenlerle hekimler, sağlık bilgisi arayıp gelen hastaya kendilerine göre en uygun iletişim stratejisini uygularlar: Hekim hastanın söyleyeceği bilgiyi reddedebilir, bilgiyi yok sayabilir veya bilgiyi kabul edebilir $(11,12)$. 
Günümüzde sağlık bilgisi araştırma davranışı hastalar arasında çok yaygındır. Hastaların bu davranışını inceleyen pek çok çalışma olmasına rağmen, bilgi arayıp gelen hastaya hekimin tutumuna yönelik çok sınırlı çalışma vardır ve günümüzün hasta-hekim iletişimde ne gibi değişikliklere yol açtığı incelenmemiştir. Bu çalışmada, Afyonkarahisar Sağlık Bilimleri Üniversitesi Tıp Fakültesi'nde Dahili ve Cerrahi Bilimlerde poliklinik hizmeti veren öğretim üyelerinin, sağlık bilgisi arayarak gelen hastaya karşı nasıl bir iletişim stratejisi kullanıldı̆̆ını araştırmak amaçlandi.

\section{Gereç ve Yöntem:}

$\mathrm{Bu}$ çalışma, Afyonkarahisar Sağlık Bilimleri Üniversitesi Tıp Fakültesi 2017-2018 Eğitim Öğretim Yılı Bilimsel Araştırma Metotları (BAM) dersi kapsamında hazırlanmış ve sunulmuştur. Fakültemizde BAM derslerinde 3. Sınıf öğrencileri küçük gruplara bölünmekte ve bir danışman öğretim üyesi eşliğinde bir araştırma planlamakta ve yürütmektedir. Dersin sonunda bu araştırma fakültemiz öğrencileri ve öğretim üyelerine hem sözlü bildiri hem de poster bildiri şeklinde sunulmaktadır.

$\mathrm{Bu}$ ders kapsamda yapılan bu araştırma, Ocak-Şubat 2018'de gerçekleştirilen nitel bir çalışmadır. Çalışmamızda, Afyonkarahisar Sağlık Bilimleri Üniversitesi Tıp Fakültesi'nde görev yapan, çalışmayı kabul eden, 18'i Cerrahi bilimler ve 12'si Dahili bilimlerde olmak üzere toplam 30 öğretim üyesi ile görüşüldü. Pediatristler ve Psikiyatristler çalışmaya dahil edilmedi.

$\mathrm{Bu}$ görüşmelerde yarı yapılandırılmış görüşme tekniği uygulandı. Açık uçlu sorularla derinlemesine görüşme metodu kullanıldı. Görüşmeler bu projede görevli öğrenciler tarafindan yapıldı. Görüşmelerden önce öğrenciler derinlemesine görüşme hakkında bildirildi ve pilot uygulamalar yapıldı.

Görüşmeler 10-30 dk. sürdü. Görüşmelerde öncelikle öğretim üyeleri çalışma hakkında bilgilendirildi ve rızaları dahilinde ses kaydı alınd. Ses kaydını reddeden katılımcıların beyanları yazılı olarak not alındı. Hem ses kaydı alınan hem de yazılı not alınan ifadeler, kaynağın ifade etmek istediği manayı tamamen ifade edip etmediğini anlamak için tekrarlanarak onaylarına sunuldu.

Görüşmemizde iki ana soru soruldu:

1)Sağlık bilgisi arayıp gelen hastaya nasıl yaklaşırsınız?

2)Bu konuda başınızdan geçen bir örnek olay var midir?

Ses kayıtları ve yazılı notlar, araştırmacılar tarafından metne döküldü. İletişim stratejilerine göre etiketlenerek gruplara ayrıldı. Sonra içerik analizi yapılarak hekimler bu tür hastalara uyguladıkları iletişim stratejilerine göre gruplandırıldı ve alıntılar yapıldı.

\section{Bulgular}

Bu çalışmada 23'ü $(\% 76,7)$ erkek, 7'si $(\% 23,3)$ kadın, toplam 30 öğretim üyesi ile görüşüldü ve çalışmaya katılanların yaş ortalaması 41,8 \pm 6,2 'di. Öğretim üyelerinin 15 'i $(\% 50,0)$ Doktor Öğretim Üyesi, 10'u $(\% 33,3)$ Doçent ve 5'i $(\% 16,7)$ Profesör'dü.

$\mathrm{Bu}$ çalışmada, görüşmelerle elde edilen metinlerin içerik analizleri sonucu, hekimler bilgi arayan hastaya karşı geliştirdikleri iletişim stratejilerine göre beş grupta topland1. Hekimlerin \% 43,3 ' $\ddot{\mathrm{u}}(\mathrm{n}=13)$ doğru bilgiyi destekleyen, \%26,7'si $(n=8)$ reddedici, \% $13,3^{\prime}$ ü $(n=4)$ tanı koyduktan sonraki süreçte destekleyen, \% 10,0'u $(n=3)$ destekleyici ve $\% 6,7$ 'si $(n=2)$ tepkisiz grubunda yer ald. $\mathrm{Bu}$ grupların cinsiyet ve bilim dallarına göre dağılımına baktığımızda, doğru bilgiyi destekleyenlerin \% 69,2'si erkek, \% 61,5'ü 
Cerrahi Tıp Bilimlerinde, reddedicilerin \% 75' $\mathrm{i}$ erkek, \% 62,5'i Dahili Tip Bilimlerinde, tanı koyduktan sonraki süreçte destekleyenlerin \% 75,0'1 erkek, tamamı Cerrahi Tıp Bilimlerinde, destekleyicilerin üçü de erkek, \%66,7'si Cerrahi Tıp Bilimlerinde ve tepkisizlerin tamamı erkek, \% 50,0’1 Dahili Tıp Bilimlerinde, 50,0'1 Cerrahi Tıp Bilimlerinde olduğu bulundu.

$\mathrm{Bu}$ grupların özellikleri ve her gruptan önemli alıntılar aşağıda yer almaktadır.

1- Doğru Bilgiyi Destekleyen: Sadece hekimin onayladığ 1 kaynaklardan elde edilen sağlık bilgisini kabul eden grup.

- Hasta anlamsiz ve tedaviyi bozacak bilgiler edindiyse düzeltme yoluna gidiyoruz. (E, 45)

- Yanlış bilgi ile geldiyse terslemek, bozmak yerine açıklıyoruz. Doğrusunu söyleyip anlatıyoruz. Bilimsel k1lavuzları kaynak gösteriyorum. Doğru kaynaklardan araştırıp gelebilir. Yanlış kaynaktan hiç araştırmasa daha iyi. $(\mathrm{K}, 36)$

- İnternetteki bilgilerin güncellenmesi lazım... Uzmanlık derneklerimiz halkı bilgilendirici, kafadaki sorunları giderici, derneğe yönelik bilgilendirme yapılabilir. İnterneti iyi de kullanabiliriz, kötüye de kullanabiliriz. Bizler yönlendirici olmalıyı... Bilgisiz insanla uğraşmak zordur ama yanlış bilgili insanla uğraşmak daha zordur... Sitenin ne kadar reklamı var? Yazan kim? Doktor mu? Ne zaman güncellenmiş bunları değerlendiririm. $(\mathrm{K}, 48)$

- Yolu siz çizip siz yönlendireceksiniz. Önemli olan araştırmaya ne kadar hakim olduğu değil, sizin yönlendirmeniz. (E, 57)

- Hasta mevcut şikayeti ile gerçekten bilgi almak amacıyla gelmişse; eğer öğrendikleri doğruysa kabul ederim. Yanlışsa düzeltirim. Bana geliş şikayeti ile merak ettiği soru farklı olunca; “zamanım yok” diyerek geçiştiririm. $(\mathrm{K}, 46)$
2- Reddedici: Sağlık bilgisi arayan hastanın, bilginin kaynağı ve doğruluğuna bakmaksızın, direkt aradığı bilgiyi reddeden gruptur.

$\mathrm{Bu}$ gruptaki hekimlere göre internet güvenilmemesi gereken bir kaynaktır, hatta şarlatandır. $\mathrm{Bu}$ bilgilerin güvenilirliği tam bir faciadır ve toplumumuzun eğitim düzeyi doğru bilgiyi yanlış bilgiden ayırt edecek düzeyde değildir.

- Hasta bir şeyi bilerek geliyor, ama çöplükten bilgi alarak geliyor...Ben onun bildiği her şeyi biliyorum...Beni zorlayacak hasta bu güne kadar gelmedi... Bana gol atmaya gelenler kendi kalelerine gol yedi....Internet çok büyük bir şarlatan. (E, 45)

- Bizim internetimiz tam bir facia. Toplum entelektüel değil...İnternetten bir şey öğrenince tek doğru buymuş gibi kabul ediyorlar...Hastalar interneti bilgi almak için değil de; hekim seçme amaçlı kullanması uygun olacaktır. (E,47)

İnternetten bilgi edinmek hatalı bir davranıştır. Hatta bu şekilde bilgilenip gelen hasta hekimi sinirlendirebilir.

- Okuduğu şeylere çok fazla güvenmemesi gerektiğini, tedaviyi doktorun söylediği şekilde uygulamasını öneririm... Bilgilenmeden gelmesi daha çok hoşuma gider. Bilgilenip gelen hastaya içten içe sinirlenebilirim. $(\mathrm{K}, 38)$

Ayrıca her hastalığın seyrinin farklı olacağı, fizik muayene ve laboratuarla desteklenmeyen bilginin işe yaramayacağını düşünen hekimler de mevcut.

- Tipta hastalik yoktur, hasta vardir. Her bulgu her hastada olmayabilir. Interneti hasta için önermiyorum. Aynı hastalığın bulguları bir hastada farklı şekilde seyrederken diğer hastalarda farklı şekilde seyredebilir. Fizik muayene kadar kuvvetli bir tanı yöntemi değildir. (E, 37)

Özellikle yanlış bilginin hastada gereksiz anksiyeteye yol açacağını düşünen hekimler var. 
- İnternetten tıbbi bilgi almak yanlıştır. Hastayı gereksiz korkuya, tedavisinin gecikmesine sebep olur. $(\mathrm{E}, 45)$

\section{3-Tanı Koyduktan Sonraki Süreçte}

Destekleyen: Bilgi araştırmasını, hekime gelmeden önce değil, hekim tarafından teşhis konulduktan sonra daha uygun olduğunu düşünen grup.

- Ben diyorum hastalığın ismi bu, araştırın. Ben bu bilgileri biliyorum. Ekstra bir bilgi çıkarsa hemen kendinizi yormayın beni arayın diyorum. (E, 38)

- Bilgi arayıp gelen hastaya, senin başına bir şey geldiğinde, kime gideceksin? Yine bana geleceksin...Ama tanısını koyduktan sonra internetten hastalarıma kendi hastalığını araştır diyorum. $(\mathrm{K}, 40)$

4-Destekleyici: Sağlık bilgisi arama davranışını direkt destekleyen grup.

- Siz araç almak istediğiniz zaman, yemek yapacağınız zaman internetten kendiniz araştırmıyor musunuz? Hastanın bilgi toplayıp gelmesini, başına geleni anlamasını isteriz... Aşinalık olunca daha kolay ilerliyoruz. (E, 39) - Interneti dozunda yararlı görüyorum. İnternette yazılan her şey kötü değil...Hastaya ön tanıyı söyledikten sonra, hasta araştırıp geldiğinde benden iyi biliyordu. (E, 29)

Hatta bu konuda kendi deneyimlerinin de olduğu bu nedenle bilgi aramayı destekleyen hekimler de mevcut.

- İnternette bir sürü farklı öneride bulunan hocalar var. Biz de internete baktık, fikir birliği yok....Bu hastalığı yaşayanların fikirlerini önerilerini dikkate almakta fayda var. $(E, 38)$

5-Tepkisiz: Hasta bilgi araştırıp geldiğinde, bilgiyi yok sayan grup. Bu grupta internetteki bilginin doğruluğunun ya da yanlışlığının bir önemi yoktur.

- Hastaya k1zmaya gerek yok, (bilgiyi) her yerden öğrenebilir. Benim için hastanın hastalığının bilgisini bilmesinin hiçbir önemi yok. Hasta ile sürtüşmenin gereği yok. $(E, 55)$

- Israrc1 olmuyorum, istediğiniz doktora gidebilirsiniz diyorum. Önyargılı olup yanlış şeyi söylüyorlarsa zorlayıcı olabiliyor. Israr etmiyorum düzeltmeye çalışmıyorum. $(\mathrm{E}, 38)$

\section{Tartışma}

Bu çalışmada, bilgi arayan hastaya karşı hekimin uyguladığ1 iletişim stratejisine göre, hekimler beş gruba ayrılmıştır. İlk sırada \%43,3' lük oranla doğru bilgiyi destekleyen hekimler yer almıştır. Doğru bilgiyi desteklemenin hastaya en iyi yaklaşım olduğu ve hasta hekim ilişkisini güçlendirildiği önceki çalışmalarda bildirilmiştir (11). Böyle bir yaklaşımla hem hasta hastalığ hakkında fikir sahibi olmakta; hem de hekim hastaya daha rahat yaklaşabilmektedir ve bu da tedavi sürecinin kolaylaşmasını sağlamaktadır (11). Önceki çalışmalarda bazı hastalar, hekimlerin kendilerini internette bilgi aramaya yönlendirdiğini söylemişlerdir. Ayrıca, internetteki bilgilerin hekimler tarafindan kontrol edilmesi gerektiğini belirtmişlerdir (13). Bizim çalışmamızda da, hekimlerin yaklaşık yarısı, hastaların doğru kaynaklardan bilgi almalarının veya kaynak konusunda kendilerine danışılmasının uygun olacağını belirtmişlerdir. $\mathrm{Bu}$ hem hekimin internetteki bilgilere güvenmemesinden, hem de bilgi edinme konusunda bile kendisine danışılmadan böyle bir davranışta bulunmasının yanlış olması düşüncesinden kaynaklıyor olabilir. Bunun dışında hastalığ 1 dışında da hekime sorular geldiği belirtilmiş, bulgularda verilen hekim örneğinde görüldüğü gibi bu tür durumlarda hekimin genellikle vakit ayırmadan geçiştirdiği görülmüştür. $\mathrm{Bu}$ durum, daha önceki bir çalışmada (11) hekimlerin sağlık bilgisi arayıp gelen hastayla iletişimde üç faktörün önemli olmasıyla açıklanmıştır. Bunlar; hastanın sağlık 
okuryazarlığ 1 , tartışılacak çevrimiçi bilgilerin uygunluğu ve hekimin iletişim etkinliği. Örneğin; sağlık okuryazarllı̆ı yüksek bir hasta tedavi sürecine daha fazla dahil olmak, ilgisiz bilgileri derinlemesine tartışmak isterse, hekim buna direnç gösterebilir. Bilgilerin uygunluğu için de genellikle hekim kendisine danışmasını önerir. Hekimin bu görüşmede verdiği tepkiler, kendi iletişim becerisini de bağlıdır. Bizim çalışmamızdaki örnekler de bunu destekler niteliktedir; hekim doğru bilgiyi desteklemesine rağmen, doğru bilginin tek kaynağ 1 kendini olduğunu belirtmesi gibi otoriter bir tavır takınabilmekte, ya da bu bilgiler ası tıbbi durumunun dışına çıktığında, ilgisiz bilgileri tartışmak istendiğinde hekim genellikle vakit ayırmadan hastayı geçiştirebilmektedir.

$\mathrm{Bu}$ çalışmada üç hekim internetteki her türlü bilgi araştırmasını desteklediklerini ifade etmişlerdir. Bazı hekimler için bilginin arandığı zaman önemliydi. Hekime başvurmadan önce yapılan aramaların kafa karıştırabileceğini, tanı konduktan sonra hastalıkları hakkında bilgi sahibi olmalarının kendilerine yarar sağlayacaklarını düşünmekteydiler.

Reddedici hekimler \%26,7 oranla ikinci sırada bulunmuştur. Hekimlerin bu tutumu sergilemesinin sebebi; hastanın internetten aldığı bilgiyi yanlış öğrenmesi, aldığı bilginin yanlış olması ve hastanın düşük eğitim düzeyi ile açıklanmıştır (11). Ancak, bu tutumun sergilenmesi hasta-hekim ilişkisinde olumsuzluklara sebebiyet vermektedir. Çünkü hasta, tanı ve tedavi sürecinde aktif bir rol almak istemektedir. Reddedici hekimlerde, doğru bilgiyi destekleyenlerin aksine, hasta-hekim arasında güven bağı oluşmamaktadır. Bazı hekimler, otoritelerini kullanarak internetten edinilen bilgilerin tartışılmasını reddetmekte, hastaların soru sorma motivasyonlarını kırmakta ve bu tür hastaları problematik olarak görmektedirler. Bu yüzden hastalar, bilgileri internetten bulduklarını hekimlerinden saklamaya çalışmaktadırlar (14).
Geleneksel olarak, sağlık profesyonelleri hastalara tanı, prognoz ve tedavi seçenekleriyle ilgili temel bilgi sağlayıcılarıydı. Bununla birlikte, internet üzerinden bilgiye kolay erişim ve ulaşılabilirliği sayesinde pek çok hasta artık bu tutumla tatmin edilmemektedir. Tamamen bilgilendirilmek ve tedaviye karar vermenin bir parçası olmak istemektedir (15). Hastalar, hekimlerin sağlıkları ile ilgili durumlar hakkında bile bilgi edinme konusunda istişareye karşı direncini yaşamışlardır (13). Buna rağmen pek çok araştırmacı interneti bir bilgi kaynağ 1 olarak kullanan hastaların tedaviye karar verme sürecine daha fazla katılımı sağladığını bulmuştur. Bununla birlikte, internetin hekim ağırlıklı hekim-hasta ilişkilerini değiştirmede etkisi yine de sınırlıdır. Geçmiş çalışmalardan elde edilen bulgular, hiyerarşik hekim-hasta ilişkilerinin, hekimlik kültüründe olduğunu göstermiştir (16). Otoriter veya paternal bir role daha alışı olan hekimler, bu daha "işbirlikçi" rolüne uyum sağlama konusunda zorluk çekebilir ve hastalara geleneksel tıp otoritesine karşı bir zorluk olarak algılanabilirler (9).

Sağlık bilgisi arama davranışının hasta-hekim ilişkilerini yıpratacağı inancının tersine, elde edilen bilgiler hekim önerilerini ve tavsiyelerini daha iyi anlamalarına yardımcı olabilecek ek bir kaynak olarak da görenler bulunmaktadır. $\mathrm{Bu}$ nedenle, geleneksel hasta-hekim ilişkisinin yapısındaki "hekimin tek bilgi kaynağ 1 olduğu algısı" da değişime uğramaktadır (7). Hekimlerin de bu tür hastaların ihtiyaç ve isteklerine uygun iletişim stratejileri geliştirmeleri zorunlu hale gelmeye başlamıştır. Bizim çalışmamızda da buna paralel bir şekilde hekimlerin büyük bir kısmı bu davranışı destekleyici yönde bir tutum sergiledikleri görülmüştür.

\section{Araştırmanın kısıtlılıkları}

$\mathrm{Bu}$ çalışmada sadece hekimin tutumu sorgulanmış, hastanın eğitim düzeyi, bilgi kaynağı ve hekime yaklaşımı gibi hastaya ait özellikler göz ardı edilmiştir. Bu nedenle bu tür 
özelliklerin de standardize edildiği daha ileri araştırmalar ihtiyaç vardır.

\section{KAYNAKLAR}

1 1.Kannampallil, TG, Franklin A, Mishra R, Almoosa, KF, Cohen T, Patel VL. Understanding the nature of information seeking behavior in critical care: implications for the design of health information technology. Artificial intelligence in medicine. 2013; 57(1): 21-29.

\section{Manafo E, Wong S. Exploring older adults'} health information seeking behaviors. J Nutr Educ Behav. 2012;44(1):85-89.

3.Anker A, Reinhart AM, Feeley TH. Health information seeking: a review of measures and methods. Patient Educ Couns. 2011 Mar; 82(3):346-354.

4.Mukherjee A and Bawden D. Health information seeking in the information society. Health Info Libr . 2012; 29(3): 242-246.

5. Sommerhalder K, Abraham A, Zufferey MC, Barth J, Abel T. Internet information and medical consultations: experiences from patients'and physicians' perspectives. Patient Educ Couns. 2009 Nov;77(2):266-271.

6. Gerber BS, Eiser AR. The patient physician relationship in the Internet age: future prospects and the research agenda. J Med Internet Res. 2001 Apr-Jun;3(2):E15.

7. Tan SS-L, Goonawardene N. Internet Health Information Seeking and the Patient-Physician Relationship: A Systematic Review. Eysenbach G, ed. Journal of Medical Internet Research. 2017;19(1):e9. doi:10.2196/jmir.5729.

8. Iverson SA, Howard KB, Penney BK. Impact of internet use on health-related behaviors and the patient-physician relationship: a surveybased study and review. J Am Osteopath Assoc. 2008 Dec;108(12):699-711.

9. Wald HS, Dube CE, Anthony DC. Untangling the Web--the impact of Internet use on health care and the physician-patient relationship. Patient Educ Couns. 2007 Nov;68(3):218-24.

10. Sabel MS, Stringfield VJ, Schwartz JL et al. Patterns of Internet use and impact on patients with melanoma. J Am Acad Dermatol. 2005; 52 : 779-85.

11. Caiata-Zufferey M, Schulz PJ. Physicians' communicative strategies in interacting with Internet-informed patients: results from a qualitative study. Health Commun. 2012;27(8):738-749.

12. Hall JA, Roter DL, Rand CS. Communication of affect between patient and physician. J Health Soc Behav. 1981;22(1):18-30.

13. Stevenson FA, Kerr C, Murray E, Nazareth I. Information from the Internet and the doctorpatient relationship: the patient perspective--a qualitative study. BMC Fam Pract. 2007;8:47.

14. Broom A. Virtually he@1thy: the impact of internet use on disease experience and the doctor-patient relationship. Qual Health Res. 2005 Mar;15(3):325-345.

15. McMullan M. Patients using the Internet to obtain health information: how this affects the patient-health professional relationship. Patient Educ Couns. 2006 Oct;63(1-2):24-8.

16. Chiu Y. Probing, impelling, but not offending doctors: the role of the internet as an information source for patients' interactions with doctors. Qual Health Res. 2011 Dec;21(12):1658-66. 